\title{
How Goals and Plans Affect Action
}

\author{
Peter M. Gollwitzer \\ Bernd Schaal \\ Universität Konstanz, Germany
}

The concepts of goals and plans have not only played an important role in research on motivation and self-regulation (Ach, 1935; Carver \& Scheier, 1981; Kruglanski, 1996; Lewin, 1926; Miller, Galanter, \& Pribram, 1960), but goals and plans and their effects on affect, behavior, and cognition have become a very popular research topic in social psychology (Frese \& Sabini, 1985; Gollwitzer \& Bargh, 1996; Halisch \& Kuhl, 1987; Pervin, 1989). The goal concept has also received recent attention in educational psychology (Snow \& Corno, 1996). Modern goal theories can be classified in two groups: (a) goal content theories, and (b) self-regulation theories of goal striving. How these goal theories contribute to theorizing about educational implications of goal setting and goal striving is discussed in this chapter.

\section{THE HISTORY OF THE CONCEPT OF GOALS}

From the behaviorist perspective, goal-directed behavior is defined by a number of observable features. Central to this definition is the persistence of behavior until the desired end-state is attained (Tolman, 1925). Besides persistence, later researchers (Bindra, 1959) pointed to the appropriateness of goal-directed behavior in the sense that the goal-directed organism adopts an effective course of action in response to barriers on the way to the goal, which subscribes to a powerful incentive (e.g., food). If, for instance, one way of goal attainment is blocked, another course of action to the same goal is taken. Likewise, when the goal changes location, the goal-directed organism readily adapts to these changes by following the goal. Finally, besides persistence and appropriateness, hyperactivity and restlessness is observed in goal-striving organisms when exposed to stimuli that are associated with a previously pursued goal. This restlessness is commonly referred to as searching for the goal. 
The observable features of goal-directed behavior compiled by behaviorist researchers (i.e., persistence, appropriateness, and searching) describe the phenomenology of goal-directed behavior from an external perspective. The behaviorist perspective falls short of what qualifies, for the individual, as an actual goal. The reference point of modern goal theories is, in contrast to the behaviorist view, exactly the internal subjective goal. Goal-directed behavior is studied in relation to goals held by the individual (e.g., a person's goal to quit smoking serves as a reference point for his or her efforts to achieve this goal). Research questions focus on whether and how setting personal goals affects a person's behaviors. This theoretical orientation has its own historical precursors that reach back far beyond the heydays of behaviorism. James' (1890) included a chapter on will in which he discussed the following question: How is it possible that a behavior that a person intends to perform (i.e., has been set as a goal by this person) fails to be executed? James referred to such problems as issues of the obstructed will, but he also raised questions related to what he called issues of the explosive will (i.e., how is it possible that an undesired behavior is performed even though a person has set the goal to suppress it?).

James' theorizing rests on the assumption that behavior can potentially be regulated by a person's resolutions (or intentions or subjective goals) even though in certain situations and at certain times it may be difficult for such resolutions to come true. In any case, the individual's subjective goal is the reference point for the goal-directed action and not a powerful incentive focused on by an outside observer (or scientist). The question raised by James is whether people meet their goals in their actions, not whether their actions toward an incentive carry features of persistence, appropriateness, and searching.

A further prominent historical figure in theorizing about subjective goals and their effects on behavior is McDougall. He explicitly saw the reference point for goal-directed behavior as being in a person's subjective purpose or goal (McDougall, 1908). He postulated that subjective goals guide a person's behavior. This guidance is thought to be achieved through cognitive activity pertaining to the analysis of the present situational context and the envisioned event or goal state to be realized. Furthermore, progress toward and attainment of the goal are seen as pleasurable experiences, whereas thwarting and failure are seen as painful or disagreeable. With respect to the observable features of goaldirected activity, however, McDougall referred to the same aspects as the behaviorists (e.g., persistence and appropriateness).

In the history of German psychology, the issue of goal-directedness of behavior played a particularly prominent role and resulted in an intensive exchange of opinions. This controversy began at the beginning of the century and lasted up to the 1930s. The main protagonists were Ach (for a summary see Ach, 1935) and Lewin (1926). In an attempt to establish a scientific analysis of the phenomenon of volitional action or willing (Willenspsychologie), Ach used a very simple paradigm. Subjects were trained to respond repeatedly and 
consistently to specific stimuli (e.g., numbers or meaningless syllables) with certain responses (e.g., to add or to rhyme, respectively). When these responses had become habitual, subjects were instructed to employ their will and execute antagonistic responses (e.g., to subtract or read, respectively). Ach discovered that forming the intention to respond to the critical stimuli with an antagonistic response helps "to get one's will." The theorizing on how an intention achieves the reliable execution of the intended action was based on the concept of determination. Ach assumed that linking, in one's mind, an anticipated situation to a concrete intended behavior creates what he called a determination and this determination would in turn urge the person to execute the intended action once the specified situational stimulus is encountered. The strength of the determination should depend on how concretely people specify the intended action and the respective situation; concreteness was thought to intensify determination. Moreover, the intensity of the act of intending (willing) should also increase determination because intensive willing induces a heightened commitment ("I really will do it!"). Determination was expected to elicit directly the intended behavior without a person's conscious intent to get started. Ach speculated that determination may affect perceptual and attentional processes so that the specified situation is cognized in a way that favors the initiation of the intended action.

Lewin (1926), in contrast, proposed a need theory of goal striving. Intentions, like needs, assign a valence (in German: Aufforderungscharakter) to objects and events in people's social and nonsocial surroundings. For a person who intends to mail a letter, a mailbox entices (or at least calls or reminds) him or her to deposit the letter, very much like food entices a hungry person to eat. Because needs can be satisfied by various types of behaviors that may all substitute for each other in terms of reducing need tension (e.g., eating fruit, vegetables, bread, and so forth), many different intention-related behaviors qualify for satisfying the quasi-need associated with an intention. The amount of the tension associated with the quasi-need was assumed to directly relate to the intensity of a person's goal strivings. The exact amount of tension may vary. First, it is affected by the degree of quasi-need fulfillment (i.e., tension comes to a final rest when the goal is achieved), but it is also thought to depend on the strength of the relevant real needs (i.e., superordinate drives and general life goals) and how strongly these are related to the quasi-need. It is assumed that people commonly see more than just one route to goal achievement (e.g., contacting a friend) and that all these routes may substitute for each other (e.g., phone, fax, e-mail, letter). In other words, an intention can be realized in many different ways and the blocking of one of them should readily lead to attempts to realize the intention through alternative routes (Lissner, 1933; Mahler, 1933; Ovsiankina, 1928).

The major difference between Ach's and Lewin's accounts of how intentions affect behavior is that Lewin employed classic motivational variables such as needs and incentives (valences) and attempted to predict the effects of intentions 
on the basis of these variables. Ach, however, focused on how people form intentions and attempted to predict the effects of intentions by the intensity of the act of intention formation and the framing of the intention. He postulated that these volitional (willing) variables function independently of the motivational basis of an intention.

\section{MODERN GOAL THEORIES}

Many of the ideas on goal-directed behaviors, as presented by James (1890), McDougall (1908), the German psychology of will, and, to a lesser degree, the behaviorists, have been adopted by modern goal theories. Today, there are no big theoretical controversies and we rarely observe experiments that critically compare different theories, but there is a wealth of different theories and ideas on goals and goal-directed behavior. In order to arrive at a comprehensive presentation of the many different theories, we have grouped them according to aspects of similarity. This has led to two major categories:

1. Content theories of goal striving, which attempt to explain differences in goaldirected behaviors and their consequences in terms of what is specified as the goal by the individual. Differences in goal content are expected to drastically affect a person's behaviors.

2. Self-regulation theories of goal striving, which attempt to explain the volitional processes that mediate the effects of goals on behavior. As we explain in this chapter, there are two different types of self-regulation theories, one of a more motivational, the other of a more cognitive nature.

\section{GOAL CONTENT THEORIES}

Goal contents vary because goals may be challenging or modest, specific or vague, abstract or concrete, proximal or distal, with a negative or positive outcome focus, and so forth. But goals may also cover different themes and issues because they can be based on different needs and incentives. Moreover, the type of implicit theory the individual holds regarding the functioning of the subject matter involved further determines goal attainment. The research strategy ado:ted by goal content theorists compares the effects of goals varying on the dimension of interest (e.g., specific vs. vague goals, goals based on autonomy needs vs. goals based on material needs) on a relevant dependent variable (e.g., quantity or quality of performance). 


\section{Goal Specificity}

The prototype of a goal content theory is the goal setting theory, put forth by Locke and Latham (1990). The basic thesis in this theory is that challenging goals that are spelled out in specific terms have a particular positive' effect on behavior. In a very large number of mainly experimental studies, challenging specific goals were superior to modest specific goals, as well as to challenging vague goals (i.e., "do your best" goals). In a typical study conducted in a work setting (Latham \& Yukl, 1975), woodworkers were sent out to the forest equipped with goals with different contents or no goals at all. Challenging goals (i.e., standards above what can be achieved with normal effort expenditure) led to a higher productivity as observed in the no-goal control group when goals were formulated in specific terms (e.g., number of trees to be cut). Specific nonchallenging goals implying modest standards failed to increase productivity, as did challenging but vague goals, such as "do your best."

\section{Needs as Sources of Goals}

Locke and Latham, in their theorizing, focused on structural features of goal content (i.e., specifity and challenge). Deci and Ryan (1991) criticized this point of view by stating that not all goals are created equal. According to Deci and Ryan, goals affect a person's behavior differently depending on the kind of need that is the source of a person's goal setting. Based on their self-determination theory, Deci and Ryan postulated that goals in the service of autonomy, competence, and social integration needs lead to better performances in the sense of greater creativity, higher cognitive flexibility, greater depth in information processing, and more effective coping with failure. Deci and Ryan argued that the respective needs are assumed to further autonomous, self-determined, and authentical goal-striving. This positive kind of goal activity is contrasted with a less effective, negative kind, which is unreflectively controlled from outside (e.g., goal assignments by authorities) or from inside (e.g., goal setting based on feelings of obligation).

\section{Implicit Theories as Sources of Goals}

A further goal content theory is suggested by Dweck (1991; Elliot \& Dweck, 1988). Dweck's theory focuses on achievement goals and postulates a distinction between learning goals and performance goals. The source of goal setting is a person's implicit theory about the nature of ability, not a person's needs, as asserted by Deci and Ryan. In an achievement situation, persons set themselves learning or performance goals depending on whether they hold an entity theory 
(i.e., they believe that the amount of ability is fixed and cannot easily be changed) or an incremental theory (i.e., they believe that the amount of ability can be improved by learning). Entity theorists try to find out via task performance how capable they are, thus making inferences on the amount of their respective talent. They set themselves performance goals. Incremental theorists want to know where and why they are making mistakes in order to learn how to improve-they set themselves learning goals. These distinct types of goals have important behavioral consequences, in particular when it comes to coping with failure. For individuals with performance goals, negative outcomes signal a lack of intelligence and thus result in helpless reactions (e.g., low persistence). People with learning goals, on the other hand, view setbacks as cues to focus on new behavioral strategies. Their behavior is oriented toward mastering the causes of the setback.

\section{Further Goal Content Theories}

Two other important distinctions of goal content theories need to be mentioned. The first is discussed by Bandura and Schunk (1981) and relates to the time frame of goal attainment. Proximal goals relate to what one does in the present or the near future, whereas distal goals point far into the future. Bandura and Schunk (1981) observed that proximal goals improved children's arithmetic attainment. This effect was mediated by an increase in the children's strength of self-efficacy and intrinsic interest in mathematics. Distal goals, however, are too far removed in time to guide a person's action effectively, as they fail to provide small successes that promote self-efficacy and interest.

A second important difference in the framing of goals has been introduced by Higgins, Roney, Crowe, and Hymes (1994) and pertains to the valence of one's goal pursuit. Achievement goals with a positive outcome focus (i.e., goals that focus on the presence or absence of positive outcomes) favor task performance, whereas goals with a negative outcome focus (i.e., goals that focus on the presence or absence of negative outcomes) undermine it. In addition, individuals with chronic discrepancies between their actual and ideal selves (i.e., people who fall short of their ideals) are found to prefer to set themselves positive outcome focus goals, whereas individuals with discrepancies between their actual and ought selves (i.e., people who fall short of their duties) prefer negative outcome focus goals.

\section{SELF-REGULATION THEORIES OF GOAL STRIVING}

As experience tells us, there is often a long way from goal setting to goal attainment. Having formed a goal is often just a first step toward goal attainment 
and requires that a host of subsequent implementational problems are solved successfully. These problems are manifold, as they pertain to initiating goaldirected actions and bringing them to a successful ending. To solve problems effectively, people step up efforts in the face of difficulties, bypass barriers, compensate for failures and shortcomings, and negotiate conflicts between goals. Self-regulation theories analyze how the individual effectively solves these problems of goal implementation. Often, these theories focus on one of these problems in particular and ignore the others. All of the self-regulation theories, however, attempt to propose general principles that apply to the problems of implementation of all goals, despite differences in content.

\section{Regulating Competing Goal Pursuits}

Kuhl (1983, 1984; Kuhl \& Beckmann, 1994) focused on self-regulatory processes that contribute to goal achievement in the face of competing action tendencies. Following Atkinson and Birch's (1970) theorizing on the dynamics of action, it is assumed that at any given point, many different action tendencies, both waxing and waning in strength, coexist. For an ordered action sequence to occur, Kuhl assumed that a current guiding goal had to be shielded from competing goal intentions. He termed this shielding mechanism "action control" and differentiated a number of control strategies, such as attention control, emotion control, motivation control, and environment control. Kuhl further assumed that whether and how effectively these strategies are employed depends on the current control mode of the individual. Two control modes are defined by Kuhl: (a) action orientation, which leads a person to concentrate on the planning and initiation of goal-directed action and to respond flexibly to the respective contextual demands effectively, using the listed control strategies, and (b) state orientation, which implies that a person cannot disengage from competing incomplete goals and is caught up in dysfunctional persevering thoughts, directed at past or future successes or failures.

Goal researchers are becoming increasingly aware that goals are not created in isolation. People set themselves many goals, and these goals may come into conflict with each other. When goals are short term, the process of shielding an ongoing goal pursuit from competing others seems most important. Other selfregulatory processes are needed, however, when the conflicting goals are enduring, such as self-defining goals (Wicklund \& Gollwitzer, 1982), personal strivings (Emmons, 1989), or life tasks (Cantor, 1994). Emmons and King (1988) observed that conflict between and within personal strivings is associated with poor well-being. Conflict was found to relate to negative affectivity and/or physical symptomatology. Emmons (1996) argued that creative integrations of a person's strivings might reverse the negative effects of conflict. 
Conflict between goals has also been discussed in the theoretical framework of life tasks (Cantor \& Fleeson, 1994). Life tasks, such as doing well academically, exert specific influences on behavior, as they are interpreted differently over the life course and across situational contexts. Life tasks are often confronted with difficulties, frustrations, anxieties, and self doubts, and the individual's style of appraising these hindrances leads to a typical pattern of action goals aimed at overcoming these obstacles. For instance, college students who worry about their abilities when they experience failure (i.e., outcomefocused individuals; Harlow \& Cantor, 1994) may, in a strategic effort to meet their academic life task, turn for reassurance to others who they regard as confidantes and encouragers. In this case, social goals are put in the service of academic goals.

\section{Regulation of Goals and Reduction of Goal Discrepancies}

If one considers a person's goal pursuit as an issue of discrepancy reduction, a host of further self-regulatory processes can be identified. Discrepancy-reduction theories of goal pursuit do not conceive of goals as something attractive (i.e., specifying a positive incentive corresponding to some vital need) that pulls the individual in the direction of goal attainment. The set goal only specifies a performance standard. Prototypical are Bandura's (1991) ideas on the selfregulation of action. According to Bandura, goals have no motivational consequences per se; they only specify the conditions that allow a positive or negative self-evaluation. If the set goal is attained through one's actions, a positive self-evaluation prevails, whereas staying below one's goal leads to a negative self-evaluation. Thus, the individual is pushed by the negative selfevaluation associated with the discrepancy, and pulled by the anticipated positive self-evaluation intrinsically linked to closing the gap between the status quo and
the goal (i.e., performance standard).

These basic ideas imply that goals stimulate effortful acting toward goal attainment (what Bandura referred to as high performance motivation) only when people recognize a discrepancy between the status quo and the set goal. Bandura therefore proposed attaining feedback as a powerful measure to stimulate goal pursuit. Moreover, people are expected to engage in effort to reduce the experienced discrepancy only when they have acquired a strong sense of selfefficacy with respect to the required actions. Doubts about possessing the capabilities necessitated by these actions undermine a person's readiness to act on the goal.

Bandura's ideas remind one of control theory as suggested by Carver and Scheier (1981). Stimulated by Miller, Galanter, and Pribram (1960), Carver and Scheier applied a control theoretical framework to the study of goal-directed action. The central conceptual unit of their analysis is the negative feedback 
loop. In a negative feedback loop, a reference criterion is compared with a perceptual input in a comparator. If there is a difference between the two, a signal is generated (i.e., an error is detected). The detected error elicits behavior that reduces the discrepancy between the reference criterion and the perceptual input. Following Powers' (1974) proposal that behavior is organized hierarchically, Carver and Scheier assumed a cascading loop structure. A positive affective response as a consequence of goal attainment is not assumed, however, nor is the detection of error associated with negative affect. Rather, the speed of progress toward a goal is seen as the source of positive or negative feelings in a person's goal pursuit. The intensity of these feelings is regulated again in a feedback loop: If the speed meets a set reference criterion, positive feelings emerge, and vice versa (Carver \& Scheier, 1990).

\section{The Model of Action Phases}

The Rubicon model of action phases (Gollwitzer, 1990; Heckhausen, 1991; Heckhausen \& Gollwitzer, 1987) stands for an integration of motivational and volitional aspects of goal setting and goal striving within a single theoretical framework. It emphasizes that distinct tasks have to be solved in the various action phases. The model assumes that a person's motives and needs produce more wishes and desires than can possibly be realized. People therefore have to make choices on the basis of deliberating the feasibility and desirability of various wishes and desires. This consideration is reminiscent of the classic motivational variables (see Atkinson \& Birch, 1970) of desirability (i.e., expected value of the goal) and feasibility (i.e., expectations on whether the goal can be realized). However, the action phases model was introduced as a critique of traditional motivational theorizing on goal-directed action in an attempt to integrate research on motivation and volition. The variables of desirability and feasibility may suffice for explaining choices of wishes and desires but they definitely fall short of explaning the implementation of a chosen goal. The model of action phases was therefore designed to explicate the differences between the motivational issue of goal choice and the volitional issue of goal implementation by taking further variables into account.

The model takes a comprehensive temporal (horizontal) view of the course of goal pursuit, which extends from the origins of a person's wishes and desires to the evaluation of the attained outcomes. The course of goal pursuit entails four different consecutive action phases. In each of these phases, a qualitatively distinct goal-attainment-related problem has to be faced in order to translate wishes into desired end-states. In the first action phase (predecisional phase), the various wishes and desires are deliberated in light of the evaluative criteria of feasibility and desirability in order to select those wishes and desires that one decides to implement. A positive decision transfers a wish or desire into a 
binding goal, which is accompanied by a feeling of determination or obligation and marks the transition into the subsequent phase. This second action phase (postdecisional and preactional phase) is characterized by the task of initiating goal-directed actions. Initiating goal-directed actions may be simple if action initiation is well practiced or routine. But if the goal-directed action is unfamiliar, complex, or one is still undecided about when and where to act, initiation of goal-directed behavior is problematic. However, by planning the when, where, and how of acting, this problem can be easily solved. With the initiation of goal-directed behaviors, the individual enters the third action phase (actional phase). The task associated with this phase is bringing goal-directed behaviors to a successful ending. For this purpose, it is necessary that the individual readily responds to opportunities that allow progress toward the goal and increases efforts in the face of difficulties and obstacles. In the final action phase (postactional, evaluative phase), the individual, after having achieved some kind of outcome, evaluates goal achievement by comparing what has been achieved with what has been desired. The individual looks back at the original deliberation and evaluation of wishes and desires that may trigger renewed deliberation and reevaluation of the feasibilities and desirabilities. As a consequence, standards of performance may be reduced or other wishes and desires may now appear more feasible and desirable, and decisions to act on a certain goal may be confirmed or altered.

\section{Action Phases and Mind-Sets}

The Rubicon model of action phases stimulated theoretical notions that help to understand people's functioning at the various stages of goal pursuit. The first notion is the distinction between deliberative and implemental mind sets. Based on the Würzburg school of thought's concept of mind-sets (Külpe, 1904; Watt, 1905), it is argued (Gollwitzer, 1990; Gollwitzer \& Bayer, 1999) that people develop corresponding mind-sets when addressing the various tasks implied by the different action phases. These mind-sets are thought to be functional for task solution and thus effectively promote people's goal pursuits.

Studies conducted on the mind-sets associated either with deliberating about one's wishes and desires (i.e., the deliberative mind-set of the predecisional phase) or with planning the initiation of goal-directed actions (i.e., the implemental mind-set of the preactional phase) support this idea: When subjects are asked to engage in intensive deliberation of whether to turn an important personal wish or desire into a goal, a cognitive orientation (i.e., the deliberative mind-set) with the following features originates: People become more openminded with respect to processing available information, and heeded information is processed more effectively while peripheral information is also encoded (Gollwitzer, 1991; Heckhausen, \& Gollwitzer, 1987). Second, people process 
information that is relevant to making decisions (e.g., desirability-related information) more effectively than implementation-related information (e.g., information on the sequencing of actions; Gollwitzer, Heckhausen, \& Steller, 1990). Finally, with respect to desirability-related information, the pros and cons of making a decision are analyzed in an impartial manner (Beckmann \& Gollwitzer, 1987). Moreover, feasibility-related information is analyzed in a relatively objective, nonillusionary way. As compared to a control group, Gollwitzer and Kinney (1989) observed reduced illusion of control judgments with subjects in a deliberative mind-set, and Taylor and Gollwitzer (1996) obtained more modest self-perceptions (on personal attributes such as creativity, intellectual ability, social intelligence) and self-evaluations (i.e., answers on the Rosenberg Self-Esteem Scale). The various features of the cognitive orientation associated with the deliberative mind-set should facilitate the making of good (i.e., realistic) goal decisions because they prevent perceiving one's wishes (i.e., the potential goals) as more desirable or feasible than they actually are.

When people are asked to plan the implementation of a chosen goal or project, a cognitive orientation (i.e., the implemental mind-set) with quite different attributes originates: People become closed-minded in the sense that they are no longer distracted by irrelevant information (Gollwitzer, 1991). They are also very effective in processing information related on implementationrelated issues (e.g., the sequencing of actions; Gollwitzer, Heckhausen, \& Steller, 1990). Moreover, desirability-related information is processed in a partial manner, favoring pros over cons (Beckmann \& Gollwitzer, 1987), and feasibility-related information is analyzed in a manner that favors illusionary optimism. This optimism extends to the illusion of control in the face of uncontrollable outcomes (Gollwitzer \& Kinney, 1989) to a person's selfperception of important personal attributes (e.g., cheerfulness, academic ability, sensitivity to others, self-respect, drive to achieve, leadership ability), and to the perceived invulnerability to both controllable and uncontrollable risks (e.g., developing an addiction to prescription drugs or losing a partner to an early death, respectively). Finally, the implemental mind-set elevates people's mood and their self-esteem. It is important to note that the mind-set effects on selfperception and perceived vulnerability to risk are not mediated by mood or selfesteem changes (Taylor \& Gollwitzer, 1996). All of the listed features of the implemental mind-set should facilitate goal achievement, as they allow the individual to effectively cope with classic problems of goal implementation, such as being distracted with irrelevant things, doubting the attractiveness of the pursued goal, or being pessimistic about its feasibility.

In summary, it appears that the stages of goal pursuit are more efficiently traversed when a person develops the appropriate mind-sets at the various phases of goal pursuit. When it comes to goal-setting, a deliberative mind-set seems most conducive. It can be created by intensively weighing the desirability and feasibility of one's wishes and desires. When it comes to the implementation of 
chosen goals, however, an implemental mind-set seems more appropriate. People can establish this mind-set by planning the implementation of their goals.

\section{Implementation Intentions Versus Goal Intentions}

A second theoretical notion stimulated by the action phases model is that of the distinction between goal intentions and implementation intentions (Gollwitzer, 1993, 1999). Implementation intentions relate to a particular form of planning where the individual commits him or herself to perform an intended goaldirected behavior when a particular situation is encountered. Implementation intentions are qualitatively distinct from goal intentions in four different aspects. First, there is the difference in format. Goal intentions are commonly the end result of the deliberation of one's wishes and desires in the predecisional phase and are formulated as "I want to achieve outcome X" (e.g., a slim body) or "I intend to achieve behavior X" (e.g., eat vegetables). Implementation intentions, however, are the result of deliberating different ways of goal attainment in the preactional phase. They specify a certain situation in which a highly specified behavior is intended to be executed and are formulated as "If situation Y (e.g., restaurant) arises, I will perform behavior Z" (e.g., order a vegetarian meal). Thus, implementation intentions link an anticipated future situation (opportunity) to a certain intended goal-directed behavior. Second, goal intentions and implementation intentions differ in their hierarchicality. Goal intentions are superordinate intentions defining a certain desired end-state, whereas implementation intentions are subordinate intentions defining the when, where, and how of a goal-directed behavior. Third, these two kinds of intentions differ in their purpose. Goal intentions are formulated in order to turn wishes and desires into binding goals and to create determination and commitment to the goal. Implementation intentions are formulated to promote goal pursuit (i.e., the initiation of goal-directed behaviors) toward an existing goal. The fourth difference relates to the distinct consequences of these two types of intentions. As a consequence of forming a goal intention, a commitment to achieving the desired end-state develops and the reduction of any realized goal discrepancy becomes an issue. Forming implementation intentions, on the other hand, creates a commitment to perform a certain goal-directed behavior in the presence of a critical situation.

Implementation intentions constitute a powerful strategy for overcoming problems in pursuing one's goals. Forming implementation intentions increases a person's readiness to terminate deliberation (Gollwitzer, Heckhausen, \& Ratajczak, 1990) and helps to get started with goal-directed actions. Goal intentions that are furnished with implementation intentions are completed more often than mere goal intentions (Gollwitzer \& Brandstätter, 1997). Implementation intentions achieve their effects by passing on the control of goal- 
directed behavior from the self to environmental cues, thus facilitating the initiation of goal-directed behaviors in the presence of the anticipated situation (specified good opportunity). It is assumed that the mental representation of the specified opportunity becomes highly activated, thus making it more accessible. Moreover, it is hypothesized that the initiation of the intended goal-directed behavior in the presence of the critical situation becomes automated. Several experimental studies were conducted to test these hypotheses (Gollwitzer, 1993, 1999).

One series of studies examined the question of whether forming implementation intentions leads to heightened activation of the mental representation of the critical stimuli. In a study by Steller (1992), the embedded figures test was used (Gottschaldt, 1926; Witkin, 1950). This test consists of geometrical figures (b-figures) that contain a smaller partial figure (a-figure). Using Gestalt principles, the a-figure is hidden in the b-figures and is thus difficult to detect. Still, following the idea that implementation intentions would lead to heightened accessibility and better detection of the a-figure, it was observed that participants showed an enhanced detection performance when they had formed implementation intentions that used the a-figure as the critical situational cue.

More evidence for the hypothesis of heightened activation of the mental representation of implementation intention relevant stimuli was found in a dichotic listening experiment by Mertin (1994). It was observed that critical words describing the anticipated situations specified in implementation intentions were highly disruptive to focused attention. Participants' performance of shadowing (i.e., efficient repeating of the words presented to the attended channel) was severely hampered when critical words were presented to the nonattended channel. Apparently, even when efforts are made to direct attention to the shadowing task, the critical words still managed to attract attention, as indicated by a weakened shadowing performance.

Finally, in a recall experiment by Seehausen, Bayer, and Gollwitzer (1994), participants were first asked to form implementation intentions with respect to performing two different tasks (a computer task and a handicraft task). Numerous ways of performing these tasks were offered (i.e., different means, different places, different times, and so forth). In a subsequent incidental recall test, participants had to recall all of the offered possible ways of performing these tasks. Participants recalled the ways they had specified in their implementation intentions better than the nonchosen ways. This was true even when the incidental recall test occurred 48 hours after participants had formed the implementation intentions.

Gollwitzer (1993, 1993) interpreted these findings by assuming that the mental representation of the anticipated situations specified in implementation intentions becomes highly activated and thus easily accessible. This has perceptual, attentional, and memory-related consequences. The situations 
specified in implementation intentions are more easily detected, more readily attended to, and more easily retrieved from memory. All of this furthers effective action initiation once the anticipated critical opportunity is encountered.

A second series of experiments dealt with the issue of the automatization of action initiation through forming implementation intentions. Implementation intentions are expected to lead to automatic initiation of the intended goaldirected behavior when the situation that was specified in an implementation intention arises. If this were true, people who have formed implementation intentions should initiate goal-directed behaviors with comparatively higher immediacy. Gollwitzer and Brandstätter (1997) exposed experimental participants to an offensive videotape in which a male made racist remarks. Participants were instructed to either form goal intentions to counterargue or goal intentions that were furnished with implementation intentions that specified good opportunities to present counterarguments. When participants were finally allowed to counterargue, implementation intention participants initiated their counterarguments more immediately when these good opportunities arose than did mere goal intention participants.

High immediacy of initiation of goal-directed behavior implies that little cognitive capacity is needed. A more direct test of the efficiency of action initiation requires a dual task experiment, however. Brandstätter (1992) performed an experiment that involved a button-pressing task embedded as the secondary task in a dual task paradigm. Participants were instructed to form the goal intention to press a button as soon as possible whenever numbers appeared on the screen but not when letters were shown. Participants in the implementation intention condition were asked to form the further intention to press the button particularly fast when the number 3 was presented. Implementation intention participants showed a substantial increase in speed (the number 3 lead to faster reactions than the other numbers) as compared to a control group. This effect was independent of whether the simultaneously demanded primary task was easy or difficult to perform. Apparently, the immediacy of responding as induced by implementation intentions is effortless in the sense that it does not put much cognitive load on limited processing resources and thus persists even when the cognitive demands of the primary task in a pair of tasks are high.

Further evidence that forming implementation intentions leads to automatization of action initiation comes from a study by Malzacher (1992). She used a retaliation paradigm (Zillmann \& Cantor, 1976) in which participants were first angered by one of the two experimenters. The second experimenter, in a subsequent phase of the experiment, encouraged the participants to retaliate. One group of participants formed the mere goal intention to retaliate, whereas another group of participants also formed implementation intentions ("As soon as I see the other experimenter again, I'll tell her what an unfriendly person she is."). Then, the second experimenter performed a reading speed task with the 
subjects that actually used a subliminal priming procedure. Pictures of the unfriendly experimenter and of a neutral person served as primes. Targets were words describing positive and negative personal attributes. Implementation intention participants read negative target words comparatively faster and positive target words comparatively slower when subliminally primed with the picture of the unfriendly experimenter as compared to the neutral picture; no such effect was observed with goal intention participants. This finding indicates that situational cues specified in an implementation intention directly elicit cognitive processes without conscious intent; in this case, the activation of relevant knowledge and the inhibition of irrelevant knowledge, which facilitate the initiation of the intended action. That implementation intentions may lead to immediate and efficient action initiation without conscious intent is also suggested by an experiment conducted by Lengfelder (1996). Lengfelder replicated the findings of Brandstätter's (1992) dual task experiment with frontal lobe patients who are known to be deficient in the conscious control of action.

The reported series of experiments suggests that forming implementation intentions not only affects the mental representation of the critical stimuli but also the initiation of the intended action. Action initiation becomes more immediate, efficient, and no longer requires conscious intent. These are all features of the automatic initiation of action and therefore it can be concluded that forming implementation intentions is a self-regulatory strategy that transforms the conscious control of action into automatic control.

The presented experiments only speak to the control of wanted behaviors through implementation intentions. But what about the control of unwanted behaviors? Schaal (1993) conducted an experiment to test whether implementation intentions support an ongoing goal pursuit by resisting a response to unwanted distractions. Subjects in this experiment had to work on a boring but strenuous task (i.e., a series of arithmetic problems) under conditions of repeated but unexpected exposure to highly disruptive distractions (i.e., clips of award-winning commercials). Subjects were either asked to form the goal intention to not let oneself get distracted or to form additional implementation intentions regarding these distractions. Two types of implementation intentions were distinguished. One group of subjects was asked to form task-facilitating implementation intentions (i.e., to work harder as soon as the distractions arise), the other group was asked to form temptation-inhibiting implementation intentions (i.e., to ignore the distractions as soon as they arise). Schaal found that implementation intentions led to higher resistance to distractions as demonstrated by a better performance on the strenuous task. Although both implementation intention groups outperformed the goal-intention-only group, the results of the implementation intention groups differentiated. Temptationinhibiting implementation intentions supported goal pursuit to a higher degree than task-facilitating implementation intentions. In two follow-up studies, Schaal and Gollwitzer (1997) explored the reasons for the superiority of temptation 
inhibiting implementation intentions over task-facilitating implementation intentions. As it turned out, task-facilitating implementation intentions produce overmotivation and thus hamper successful performance in the ongoing goal pursuit. This implies that task-facilitating implementation intentions can only be expected to show effects when the motivation to perform the ongoing goal pursuit is not very high. If this motivation is high, however, people are better off forming temptation-inhibiting implementation intentions, as this type of implementation intention guarantees effective goal pursuit independent of one's motivation to be successful.

\section{EDUCATIONAL IMPLICATIONS OF MODERN GOAL THEORIES}

The goal theories just described have educational implications, because different goal-setting and goal-striving strategies should have differential educational impacts. In what ways can educators and their students learn from these theories and the extensive research findings concerning goals? Two questions seem to be central for the application of what is known about the consequences of goal setting and goal striving in educational and instructional settings. First, there is the question of the consequences of goal setting and second, the question of how goal regulation plays its role. These two issues are discussed next on the basis of the goal content and goal regulation theories reported previously.

\section{How Should Goals Be Framed?}

As known by the work of Locke and Latham (1990), goal attainment is more likely when challenging goals are formulated in a highly specific manner. The superiority of specific goals lies in the concreteness of defining what is to be attained. In educational settings, this can be achieved by concrete definitions of what should be learned how much and until when. For example when a student tries to learn how to solve complex arithmetic problems, the learning should be more effective when learning goals are set in terms of concrete step-by-step goals and the amount of time for learning the single steps is explicitly defined. "Do-your-best" goals, however, should lead to less time spent on these problems (more breaks and earlier termination of studying). The practicing of already acquired arithmetic skills should also benefit from setting goals that concretely specify the amount of time of practicing, the amount of problems to be practiced, or both. Following Deci and Ryan (1991), however, such learning or exercise goals should always be embedded into students' autonomy and competence needs. Although solving algebraic equations, for instance, may not immediately appeal to these needs, educators will have to create such links by highlighting the long-term consequences of acquiring mathematical skills. 
The educational implications of Dweck's (1991) theory on the impact of people's implicit theories on goal setting relate to teachers and students alike. It is the educator's task to evaluate their students' performance, to give feedback in a way that provides students with sufficient information about their past performance, and to give hints and advice on how to do better in the future. But the teacher's giving of feedback should depend on their implicit theories about their students' abilities and capabilities. Teachers who favor an entity theory about students' abilities and talents should differ in their feedback from teachers who favor incremental theories about abilities and talents. Teachers with entity theories should be characterized by making global judgments, having fixed opinions about the capabilities of individual students, and verification of these opinions via biased information processing. As a consequence, self-fulfilling prophecies and labeling effects should be observed on the side of the students. Teachers who favor incremental theories, on the other hand, should be characterized by giving feedback that aims at improving each individual student's abilities (i.e., feedback that focuses on possible changes and installs a mastery orientation in students). Giving such feedback requires an individuated information processing of students. Teachers' reflecting on their own implicit theories appears to be a prerequisite for promoting incremental theories in their students. Teachers who hold entity theories do not seem to be able to install incremental theories with their students, who in turn will have to learn without the volitional benefits associated with incremental theories about abilities and talents.

But the students' implicit theories about their capabilities and talents are important as well. Students holding an entity theory about their abilities differ in many ways from students who hold incremental theories. According to Dweck (1991, 1996), entity theorists (i.e., personal attributes such as intelligence are perceived as fixed and stable) make self-evaluations that focus on the amount of talent one possesses, which in turn leads to retreat and self-punishment in the case of failure experiences. Implicit entity theorists prefer to set themselves performance goals that are known to be correlated with negative outcome expectancies, low appraisal of self-efficacy, fear of failure, and inferior performance (Elliot \& Church, 1997). Implicit incremental theorists, on the other hand, aim to develop their personal attributes (e.g., intelligence). They therefore prefer to set themselves learning goals, as they need to understand the dynamics of improving their standing on these attributes. Failure experiences thus lead to analyzing the conditions and processes responsible for the negative outcome. Learning goals and the associated striving for mastery are correlated with positive outcome expectancies, high self-efficacy appraisals, and hope for success and superior performance. Thus, concluding from Dweck's (1991) theorizing, educators should not only adopt incremental theories and set themselves learning goals with respect to the promotion of their students' 
capabilities, they should also help their students adopt such theories and set themselves learning goals.

Finally, distinguishing between positive versus negative outcome focus seems also relevant to goal-setting in educational settings. Teachers and students should avoid framing their educational goals in terms of a negative outcome focus (i.e., the focus is on the presence and absence of negative outcomes: "If I fail to attain the goal, this will be horrible" or "I simply have to avoid being a failure", respectively). Rather, setting goals that are framed with a positive outcome focus is called for (i.e., the focus is on the presence and absence of positive outcomes: "If I succeed in attaining the goal, this will be wonderful" or "Not succeeding on the goal will make me sad," respectively). Focusing on positive outcomes favors task performance and persistence in the face of difficulties, whereas a negative outcome focus undermines performance and persistence (Higgins et al., 1994). Highlighting the negative consequences of failing to meet educational goals is thus a counterproductive instructional strategy that leads to decreased effort, decreased persistence and inferior performance.

It appears then that promoting efficient learning in educational settings is not only a matter of good teaching in the sense of making it easier for students to cognitively grab the presented materials, but it is also a matter of goal setting. If educational settings induce the framing of goals that are challenging and highly specific, related to students' autonomy and competence needs, and focused on improving one's standing and on positive outcomes rather than negative outcomes, learning should be more interesting, successful, and persistent. Certainly, there should be further goal-framing dimensions other than the ones we have named so far that are relevant in educational contexts. One of these is the dimension of proximity of the goal. Proximal goals should benefit learning more than distal goals, as the latter provide fewer opportunities to receive feedback on one's progress toward the goal (Bandura \& Schunk, 1981).

\section{How Should Goals Be Regulated?}

Progress toward educational goals can be blocked because they fall prey to competing goals (e.g., leisure-activity goals). In order to regulate competing goal pursuits, students may engage in a number of different control strategies such as attention control, emotion control, motivation control, and environment control. Engaging in these control strategies, the student develops an action orientation that is described by Kuhl $(1983,1984)$ as the counterpart of state orientation, which is associated with failing to disengage from competing incomplete goals and being caught up in persevering thoughts. Educators should therefore instruct students in the use of these control strategies, thus enabling them to shield a current, guiding goal from other competing goals. Becoming involved with the 
named action control strategies leads, according to Kuhl $(1983,1984)$, to the effective implementation of ongoing goal pursuits.

However, progress toward educational goals may become problematic when goals contradict each other (for instance, the conflict between goals of becoming an expert in some academic field versus goals related to personality development). Such conflicts between self-defining goals (Wicklund \& Gollwitzer, 1982), personal strivings (Emmons, 1989), or life tasks (Cantor, 1994) were found to relate to negative affectivity and poor well-being. Encouraging the creative integration of such conflicting goals should therefore be a prominent task of educators (Emmons, 1996), because solving such conflicts allows for successful personality development across the life span.

Bandura (1991) considered a person's goal pursuit as a reduction of discrepancies between an actual situation and a to-be-attained end-state. Goals, per se, do not motivate a person to act toward a desired end-state; rather, it is the detection of a discrepancy between the actual state and the desired end-state and the anticipated reduction of this discrepancy. The detection of discrepancies thus plays a primary role. In many educational settings, goal discrepancies arise when the teacher or educator gives performance feedback. The person who gives feedback should thus ensure that the feedback is objective and reflects the discrepancy that still exists. As only high self-efficacious individuals set out to reduce discrepancies, the feedback should also inform the student on how to reduce the discrepancy. Feedback that focuses only on the existing discrepancy should be sufficient only for students who feel highly self-efficacious to begin with.

A very effective volitional strategy that educators can suggest to their students is the planning of goal-directed actions. One of the effects of planning is that it stops reflections on whether to pursue a certain goal or not (Gollwitzer, Heckhausen, \& Ratajczak, 1990). Planning the implementation of a chosen goal moreover leads to an implemental mind-set that promotes biased processing of desirability-related information in the way of favoring the pros over the cons of the chosen goal. Planning also produces positive illusions about the feasibility of a chosen goal (Gollwitzer \& Kinney, 1989; Taylor \& Gollwitzer, 1996) that affects the perception of one's personal attributes as well as one's vulnerability to risks, resulting in an optimistic view of goal attainment. If students are taught how to generate implemental mind-sets, they will develop the illusory optimism and partiality that favors goal attainment. Illusionary optimism is needed in particular when goals are hard to achieve, take a lot of effort, and potentially are important in the long run but not that attractive to strive for at the moment.

As Gollwitzer and his colleagues (1993, 1996; Gollwitzer \& Schaal, 1998) demonstrated, forming simple implementation intentions has beneficial effects on getting started with an intended goal-directed action. Implementation intentions produce a perceptual readiness for good opportunities on which a 
person intends to act, a disruption of focused attention, and a behavioral readiness to initiate the intended goal-directed behavior. Control over action initiation is given to an environmental stimulus that is highly accessible and when present initiates the respective goal-directed behavior automatically. Implementation intentions also support persistence in the face of distractions and temptations to give up the ongoing pursuit of a goal. They also lead to superior recall of goal-related information preventing one from forgetting of how to perform a given goal. These activation and automatization effects arise from a rather simple mental act of linking a certain anticipated situation to an intended goal-directed behavior. This kind of volitional tool is easy to use, has low costs concerning time and capacity, but still has pronounced consequences for controlling one's own behavior in order to attain certain goals. Educators should thus inform students about the existence of this tool and how it is used. In addition, educators should help their students to identify good opportunities and appropriate behaviors for goal attainment. Forming implementation intentions can be learned by guided mental simulations and it can be practiced in all kinds of contexts, such as playing games or exercising. That implementation intentions can be used successfully in educational settings has been demonstrated by Orbell, Hodgkins, and Sheeran (1997), who observed that it is much easier to lead people to perform health-maintaining behaviors when they are encouraged to form respective goal intentions that are furnished with implementation intentions.

\section{Volitional Tools}

In this chapter we have brought together various prominent goal theories that describe how people attain their goals. This theoretical work on goal attainment and volition can be analyzed in terms of the question of what kind of volitional tools can be suggested to students in order to better enable them to attain their goals, even under difficult circumstances. Students should learn to use these various instruments of volition in combination to set goals and regulate goals in a way that makes goal attainment more likely. We know that our perspective focuses only on one side of the education of willing - the use of volitional tools-and does not take into account the issue of promoting goals that focus on self-discipline and other personal attributes related to the character trait of willpower. Nevertheless, we believe that giving a volitional toolbox to students is highly important to help students to achieve responsibility, maturity, and selfreliance.

In our view, educators should aim at training their students in the use of effective goal setting and goal regulation strategies in their everyday goal pursuits. Providing tools that students can use to achieve their educational goals strikes us as being an important aspect of education and personality 
development. Acquiring goal setting and goal regulation strategies is not a formal training of the character trait of willpower, but an attempt to develop an arsenal of cognitive self-regulatory skills that can be used at will to attain what we have decided to strive for.

\section{REFERENCES}

Ach, N. (1935). Analyse des Willens. In W. Abderhalden (Eds.), Handbuch der biologischen Arbeitsmethoden (Bd. 6). Berlin: Urban \& Schwarzenberg.

Atkinson, J. W., \& Birch, D. (1970). The dynamics of action. New York: Wiley.

Bandura, A. (1991). Self-regulation of motivation through anticipatory and self-reactive mechanisms.In R. Dienstbier (Ed.), Nebraska Symposium on Motivation: Perspectives on motivation (pp. 69-164). Lincoln: University of Nebraska Press.

Bandura, A., \& Schunk, D. H. (1981). Cultivating competence, self-efficacy, and intrinsic interest through proximal self-motivation. Journal of Personality and Social Psychology, 41, 586-598.

Beckmann, J., \& Gollwitzer, P. M. (1987). Deliberative vs. implemental states of mind: The issue of impartiality in pre- and postdecisional information processing. Social Cognition, 5, 239-279.

Bindra, D. (1959). Motivation. New York: Ronald Press.

Brandstätter, V. (1992). Der Einfluß von Vorsätzen auf die Handlungsinitiierung: Ein Beitrag zur willenspsychologischen Frage der Realisierung von Absichten. Frankfurt am Main: Peter Lang.

Cantor, N. (1994). Life task problem solving: Situational affordances and personal needs. Personality and Social Psychology Bulletin, 20, 235-243.

Cantor, N., \& Fleeson, W. (1994). Social intelligence and intelligent goal pursuit: A cognitive slice of motivation. In W. Spaulding (Ed.), Nebraska Symposium on Motivation: Integrative views of motivation, cognition, and emotion (Vol. 41, pp. 125-179). Lincoln: University of Nebraska Press.

Carver, C. S., \& Scheier, M..F. (1981). Control theory: A useful conceptual framework for personality, social, clinical, and health psychology. Psychological Bulletin, 92, 111-135.

Carver, C. S., \& Scheier, M. F. (1990). Origins and functions of positive and negative affect: A control process view. Psychological Review, 97, 19-35.

Deci, E. L., \& Ryan, R. M. (1991). A motivational approach to self: Integration in personality. In R. Dienstbier (Ed.), Nebraska Symposium on Motivation: Perspectives on motivation (pp. 237288). Lincoln: University of Nebraska Press.

Dweck, C. S. (1991). Self-theories and goals: Their role in motivation, personality, and development. In R. Dienstbier (Ed.), Nebraska Symposium on Motivation: Perspectives on motivation (pp. 199-255). Lincoln: University of Nebraska Press.

Dweck, C. S. (1996). Implicit theories as organizers of goals and behavior. In P. M. Gollwitzer \& J. A. Bargh (Eds.), The psychology of action: Linking cognition and motivation to behavior (pp. 69-90). New York: Guilford.

Elliot, A. J., \& Church, M. A. (1997) A hierarchical model of approach and avoidance achievement motivation. Journal of Personality and Social Psychology, 72, 218-232.

Elliott, E. S., \& Dweck C. S. (1988). Goals: An approach to motivation and achievement. Journal of Personality and Social Psychology, 54, 5-12.

Emmons, R. A. (1989). The personal strivings approach to personality. In L. A. Pervin (Ed.), Goal concepts in personality and social psychology (pp. 87-126). Hillsdale, NJ; Lawrence Erlbaum Associates.

Emmons, R. A. (1996) Striving and feeling: Personal goals and subjective well-being. In P. M. Gollwitzer \& 3. A. Bargh (Eds.), The psychology of action (pp. 313-337). New York: Guilford. 
Emmons, R. A., \& King, L. A. (1988). Conflict among personal strivings: Immediate and long-term implications for psychological and physical well-being. Journal of Personality and Social Psychology, 54, 1040-1048.

Frese, M., \& Sabini, J. (Eds.). (1985). Goal-directed behavior: The concept of action in psychology. Hillsdale, NJ: Lawrence Erlbaum Associates.

Gollwitzer, P. M. (1990). Action phases and mind-sets. In E. T. Higgins \& R. M. Sorrentino (Eds.), Handbook of motivation and cognition (Vol. 2, pp. 53-92). New York: Guilford.

Gollwitzer, P. M. (1991). Abwägen und Planen. Göttingen: Hogrefe.

Gollwitzer, P. M. (1993). Goal achievement: The role of intentions. In European Review of Social Psychology, 4, 141-185.

Golwitzer, P. M. (1999). Implementation intentions. Strong effects of simple plans. American Psychologist, 54, 493-503.

Gollwitzer, P. M., \& Bayer, U. (1999). Deliberative and implemental mindsets in the control of action. In S. Chaiken \& Y. Trope (Eds.), Dual process theories in social psychology (pp. 403422). New York: Guilford.

Gollwitzer, P. M., \& Bargh, J. A. (Eds.). (1996). The psychology of action: Linking cognition and motivation to behavior. New York: Guilford Press.

Gollwitzer, P. M., \& Brandstătter, V. (1997). Implementatin intentions and effective goal pursuit. Journal of Personality and Social Psychology, 73(1), 186-199.

Gollwitzer, P. M., \& Kinney, R. A. (1989). Effects of deliberative and implemental mind-sets on the illusion of control. Journal of Personality and Social Psychology, 56, 531-542.

Gollwitzer, P. M., Heckhausen, H., \& Ratajczak, H. (1990). From weighting to willing: Approaching a change decision through pre- or postdecisional mentation. Organizational Behavior and Human Decision Processes, 45, 41-65.

Gollwitzer, P. M., Heckhausen, H., \& Steller, B. (1990). Deliberative and implemental mind-sets: Cognitive tuning toward congruous thoughts and information. Journal of Personality and Social Psychology, 56, 531-542.

Gollwitzer, P. M., \& Schaal, B. (1998). Metacognition in action: The importance of implementation intentions. Personality and Social Psychology Review, 2, 124-136.

Gottschaldt, K. (1926). Über den Einfluß der Erfahrung auf die Wahrnehmung von Figuren. I. Über den Einfluß gehaufter Einprägung von Figuren auf ihre Sichtbarkeit in umfassenden Konfigurationen. Psychologische Forschung, 8, 261-317.

Halisch, F., \& Kuhl, J. (1987). Motivation, intention, and action. Berlin: Springer-Verlag

Harlow, R. E., \& Cantor, N. (1994). The social pursuit of academics: side-effects and 'spillover' of strategic reassurance seeking. Journal of Personality and Social Psychology, 66, 386-397.

Heckhausen, H. (1991). Motivation and action. New York: Springer Verlag.

Heckhausen, H., \& Gollwitzer, P. M. (1987). Thought contents and cognitive functioning in motivational versus volitional states of mind. Motivation and Emotion, 11, 101-120.

Higgins, E. T. (1996). Ideals, oughts, and regulatory focus: Affect and motivation from distinct pains and pleasures. In P. M. Gollwitzer \& J. A. Bargh (Eds.), The psychology of action: Linking cognition and motivation to behavior (pp. 91-114). New York: Guilford.

Higgins, T. E., Roney, C. J. R., Crowe, E., \& Hymes, C. (1994). Ideal versus ought predilections for approach and avoidance: Distinct self-regulatory systems. Journal of Personality and Social
Psychology, 66, 276-286.

James, W. (1890). Principles of psychology. New York: Holt.

Kruglanski, A. W. (1996). Goals as knowledge structures. In P. M. Gollwitzer \& J. A. Bargh (Eds.), The psychology of action: Linking cognition and motivation to behavior (pp. 599-618). New
York: Guilford.

Kuhl, J. (1983). Motivation, Konflikt und Handlungskontrolle. Berlin: Springer-Verlag.

Kuhl, J., \& Beckmann, J. (Eds.). (1994). Volition and personality: Action versus state orientation. Gottingen, Germany: Hogrefe \& Huber.

Kuhl, J. (1984). Volitional aspects of achievement motivation and learned helplessness: Toward a comprehensive theory of action control. In B. A. Maher \& W. B. Maher (Eds.), Progress in experimental personality research (pp. 99-171). New York: Academic Press. 
Kulpe, O. (1904). Versuche uber Abstraktion. Bericht über den Kongress für experimentelle Psychologie, 1, 56-68.

Latham, G. P., \& Yukl, G. A. (1975). Assigned versus participative goal setting with educated and uneducated wood workers. Journal of Applied Psychology, 60, 299-302.

Lengfelder, A. (1996). Die Bedeutung des Frontalhirns beim Abwägen und Planen. Frankfurt am Main: Peter Lang.

Lewin, K. (1926). Vorsatz, Wille und Bedürfnis. Psychologische Forschung, 7, 330-385.

Lissner, K. (1933). Die Entspannung von Bedürnissen durch Ersatzhandlungen. Psychologische Forschung, 18, 218-250.

Locke, E. A., \& Latham G. P. (1990). A theory of goal setting and task performance. Englewood Cliffs, NJ: Prentice-Hall.

Mahler, W. (1933). Ersatzhandlungen verschiedenen Realitătsgrades. Psychologische Forschung, 18, 27-89.

Malzacher, J. T. (1992). Erleichtern Vorsätze die Handlungsinitiierung? Zur Aktivierung der Vornahmehandlung. Unpublished doctoral dissertation, Ludwig-Maximilians-Universitat, Müchen.

McDougall, W. (1908). Introduction to social psychology.. London: Methuen.

Mertin, M. (1994). Aufmerksamkeitszuwendung bei vorgenommenen Gelegenheiten. Unpublished diploma thesis, Heinrich-Heine-Universitat, Dusseldorf.

Miller, G. A., Galanter, E., \& Pribram, D. H. (1960). Plans and the structure of behavior. New York: Harper.

Orbell, S., Hodgkins, S., \& Sheeran, P. (1997). Implementation intentions and the theory of planned behavior. Personality and Social Psychology Bulletin, 33, 209-217.

Ovsiankina, M. (1928). Die Wiederaufnahme unterbrochener Handlungen. Psychologische Forschung, $11,302-379$.

Pervin, L. A. (Ed.). (1989). Goal concepts in personality and social psychology. Hillsdale, NJ: Lawrence Erlbaum Associates.

Powers, W. T. (1974). Behavior: The control of perception. London: Wildwood.

Schaal, B. (1993). Impulskontrolle: Wie Vorsätze beherrschtes Handeln erleichtern. Unpublished master's thesis, Ludwig-Maximilians-Universitat München.

Schaal, B., \& Gollwitzer, P. M. (1997, March). Impulskontrolle: Intentionseffekte bei der Handlungssteuerung. Paper presented at the 39. Tagung experimentell arbeitender Psychologen, Humboldt-Universitat zu Berlin.

Seehausen, R., Bayer, U., \& Gollwitzer, P. M. (1994, September), Experimentelle Arbeiten zur vorsatzlichen Handlungsregulation. Paper presented at the 39 . Kongre $\beta$ der Deutschen Gesellschaft fur Psychologie, Hamburg.

Snow, R. E., \& Corno, L. (1996). Individual differences in affective and conative functions. In D. C. Berliner \& R. C. Calfee (Eds.), Handbook of educational psychology (pp. 243-310). New York: Prentice Hall.

Steller, B. (1992). Vorsätze und die Wahrnehmung günstiger Gelegenheiten. München: tuduv Verlagsgesellschaft.

Taylor, S. E., \& Gollwitzer, P. M. (1996). The effects of mind-sets on positive illusions. Journal of Personality and Social Psychology, 69, 213-226.

Tolman, E. C. (1925). Purpose and cognition: The determinants of animal learning. Psychological Review, 32, 285-297.

Watt, H. (1905), Experimentelle Beiträge zu einer Theorie des Denkens. Archiv für die gesamte Psychologie, 4, 289-436.

Wicklund, R. A., \& Gollwitzer, P. M. (1982). Symbolic self-completion. Hillsdale, NJ: Lawrence Erlbaum Associates.

Witkin, H. A. (1950). Individual differences in ease of perception of embedded figures. Journal of Personality, 19, 1-15.

Zillmann, D., \& Cantor, J. R. (1976).Effect of timing of information about mitigating circumstances on emotional responses to provocation and retaliatory behavior. Journal of Experimental Social Psychology, 12, 38-55. 